\title{
Statement
}

This paper has not been published elsewhere and it has not been submitted simultaneously for publication elsewhere.

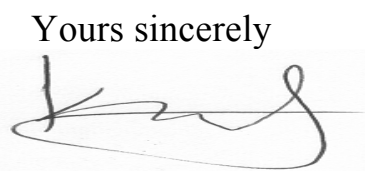

Konstantinos Kouriatis

Counselling Psychologist in Training 


\section{Therapists' Bereavement and Loss Experiences: A Literature Review}

Shortened version of the title for the running head

Therapists' Bereavement: A Literature Review

Authors' names: *Konstantinos Kouriatis and Dora Brown

PsychD Psychotherapeutic \& Counselling Psychology, University of Surrey, UK

\section{*Author Note}

Correspondence concerning this article should be addressed to:

*Konstantinos Kouriatis,, Psychotherapeutic \& Counselling Psychology, University of Surrey, GU2 7XH, UK.

E-mail: c.kouriatis@surrey.ac.uk 
Therapists' Bereavement and Loss Experiences: A Literature Review

Konstantinos Kouriatis and Dora Brown

Psychotherapeutic \& Counselling Psychology, University of Surrey, UK

\begin{abstract}
This paper reviews literature on therapists' bereavement and loss experiences. The review also looks at literature that reflects how these experiences affect therapists personally and professionally. In order to have a holistic, elaborate and flexible view on loss, this review uses acknowledgesalso the main existing theories of bereavement. Therapists' bereavement and loss experiences, are presented within three different contexts namely: the death of a close related kin, the end of therapy due to clients' death and other types of personal losses. The paper ends with recommendations for possible future research into the area.
\end{abstract}




\section{Introduction}

Loss is a recurrent theme in human life, always present and bound with life. Extensive research has been conducted on bereavement and grief however, there seems to be paucity in the area of therapists' significant loss experiences. Beutler, Malik, Alimohamed, Harwood, Talebi, Noble, and Wong (2004) have also noted the dearth of research on being a therapist. This type of negligence probably occurs because of the therapists' professional role, in which more attention is paid to clients' difficulties and well-being. This paper supports that specifically the research on therapists' bereavement calls for greater attention due to the increased frequency and idiomorphic characteristics of the losses that mental health practitioners experience. Therapists encounter loss both in their personal and working environments. Some types of losses may be further "complicated" since they might refer to non-kin or professional relationships that aren't usually socially or individually sanctioned as losses (Doka, 1989). Of course, personal losses can have a great impact not only on therapists', but also on any individual's belief system, way of thinking, feeling, acting, and relating to self and others. However, this impact becomes even more crucial and important in the case of the therapist where one's own self seems to be the most important therapeutic tool. Hopefully, more research on therapists' significant loss experiences will facilitate the reflection in one's own losses and their possible impact in clinical practice, thus contributing to the improvement in quality of counselling services. Nouwen stated:

“A deep understanding of one's own pain makes it possible to convert weakness into strength and to offer one's own experience as a source of healing to those who are often lost in the darkness of their own misunderstood sufferings." (p. 87; 1972, as cited in Hayes, Yeh and Eisenberg, 2007). 
The aim of this paper is to review relevant literature on therapists' experiences of significant losses and how these may affect them personally, and professionally. For the purpose of the review, the terms psychotherapist, therapist and mental health practitioner are used to describe any individual who offers psychotherapeutic services. Furthermore, in order to have a holistic and flexible view on loss within therapists lives, , this paper will reviewthe main existing theories of bereavement since it seems that each theory looks from a different angle at this complicated and unique process, and different studies have used different theories to present their findings.

\section{The concepts of loss, bereavement, grief and mourning}

To begin with and in order to have a better understanding of the terminology used in the literature it seems mandatory to refer to some essential terms. The concepts of loss, bereavement, grief and mourning can vary in meaning depending on the different grief theorists. This article encompasses the view that loss may stem not only from death but also from any kind of ending of a significant and meaningful attachment. Furthermore, it may be any type of loss that has a great impact on a person's thoughts, beliefs, feelings, behaviour, and relationships to self and others.

Bereavement is widely understood as the state of having experienced a significant loss (Corr, Nabe \& Corr, 2000; Rando, 1995). Grief has been defined by Raphael (1984) as the emotional reaction to loss. However, Parkes and Weiss (1983), Rando (1995), Stroebe, Hansson, Schut and Stroebe (2008), and Worden (2002) argue that grief responses incorporate the emotional, cognitive, physical, behavioural and social human functioning. Cook and Dworkin (1992), and Corr et al., (2000) also commented on the spiritual aspects of grief. Mourning has been interpreted as the "observable expression of grief" (Parkes \& Weiss, 1983), "the public display of grief" (Stroebe at al., 2008), and a phenomenon that is 
closely related with social and cultural expectations (Brabant, 2002). Corr (2002) argues that mourning can incorporate both the interpersonal, social efforts to cope with a loss and the intrapersonal, private struggles to manage and incorporate in one's life a loss and the subsequent grief. Below, different theories of grief and mourning are examined.

\section{Grief and mourning}

To better understand the phenomenon of loss and grief, it seems essential to have a look at the main theories on the field since there is not currently "a broadly applicable, integrative theory of bereavement" (Stroebe, Stroebe, \& Hansson, 1993, p.7).

\section{Stage Theories}

Bowlby $(1961,1973,1980)$ used phases in order to describe the process of adjusting to a world without the lost object. Parkes (1972) and Raphael (1984) also adopted his phasic model while making some adjustments which??. Bowlby applied his attachment theory to grief and loss. He described four phases of grief. Phase I is characterised by emotional numbing and disbelief that the attachment figure has been lost. In phase II yearning and searching of the attachment figure takes place. In phase III the bereaved person experiences disorganization and despair. Finally, phase IV is characterised by a reorganization of the representations of the deceased that allow the bereaved to continue his everyday activities and reengage in social relationships. Bowlby incorporated both the process of disconnection and of continuous connection with the deceased. Fraley and Shaver (1999) stated that within attachment theory a "recovery" from a loss "entails finding a way to maintain a secure bond with the attachment figure while simultaneously acknowledging that the person is not physically available to provide comfort and care" (p.754). The attachment style (secure, avoidant, ambivalent) with the deceased might affect the grief process. It seems that specific 
attachment styles may lead to particular grief reactions (Fraley \& Shaver, 1999; Shaver \& Tancredy, 2001). Thus, people with an anxious-ambivalent attachment style may have greater possibility of experiencing chronic grief. However, healthy mourning might be different for individuals with different attachment styles (Fraley \& Shaver, 1999; Servaty-Seib, 2004). Therefore, people with an avoidant style who do not express grief may actually react quite normally since they didn't have a strong bond with the deceased person. Recently, in an attempt to clarify any misconceptions about Bowlby's theory, Stroebe et al. (2008) argued that Bowlby didn't think of the grief stages as prescriptive of where bereaved persons should be at any particular point of time in their bereavement.

Another stage theory emerged from Kübler-Ross's work with dying patients and not mourning survivors. Kübler-Ross's (1969) five stages of grief were denial, anger, bargaining, depression, and acceptance. Kübler-Ross argued that not all people experience these stages, nor are they necessarily linear; nevertheless, they were mainly used in an inflexible and prescriptive way and were also applied to bereavement.

Sanders $(1989,1999)$ described five phases of the grieving process: shock, awareness of loss, conservation withdrawal, healing, and finally renewal. Shuchter and Zisook (1993) also offered a stage theory in which the bereaved person initially experiences shock and disbelief, then somatic, emotional discomfort and social withdrawal, and finally enters the stage of restitution.

Overall, stage theories have provided a framework to understand, observe, and study grief. However, as they can normalise people's experience, they can also create a 'should' or 'must' of grief responses when misapplied. This can result in causing further stress to people who can not identify themselves within these stages (Servaty-Seib, 2004). Corr (1993) argued that one does nott have to think in terms of specific grief responses that proceed in a linear fashion and that stage theories don't have to be seen as 'prescriptions' for the right way of 
experiencing grief. Therefore, the uniqueness of the grief experience for individuals must be taken into account (Neimeyer, 1999).

\section{Mourning theories}

Another type of theory often found in the literature is task theories of mourning. Mourning can be described as the active process of coping with bereavement and grief (Rando, 1995). Task theories of mourning ascribed an active role to the bereaved person supporting that the grieving process is not passive and does not come in the form of stages but rather the individuals can "work through" their grief and thus play a major part in how a loss experience will affect them.

Theorization about grief began with Freud's (1917/1957) Mourning and Melancholia. According to Freud, grief's function is to detach thoughts and feelings from the dead so that the bereaved persons can re-invest their libinal energy to new relationships and thus move on with their life. This is accomplished through an active process, which was later termed "grief work", whereby the attachment to the dead person is gradually abandoned through reflection and confrontation of loss related thoughts and of the past relationship. Freud believed that pathological grief was the result of either avoidance of grief work or ambivalent and conflicting feelings about the dead person. However, recent theories and therapeutic work suggest that it is adaptive for bereaved people to maintain a connection to the deceased through a "continuing bond" (Klass, Silvermann \& Nickman, 1996; Walter, 1996, 1999).

Rando $(1993,1995)$ argued that the processes of mourning were to recognise the loss, to react to the separation, to recollect and experience the deceased and the relationship, to relinquish the old attachments to the deceased and the old assumptive world, to readjust in order to move adaptively into the new world without forgetting the old, and finally to reinvest. 
Worden $(1982,1991,2002,2009)$ also supported a task model for mourning. His four-task model became quite popular and had a major change overtime. The first task for a person is to accept the reality of the loss and the second to process the pain of grief. The third task for an individual is to adjust to a world without the deceased. There are three areas of adjustment: one's everyday functioning, one's sense of self and finally one's beliefs, values and assumptions about the world. The fourth and final task is "to find an enduring connection with the deceased in the midst of embarking on a new life", (Worden, 2009, p.50). When Worden (1982) wrote the first edition of his book Grief Counseling and Grief Therapy, he adopted Freud's (1917/1957) view that the "aim" of grief work and mourning is to detach oneself from the deceased. In 1991's and 2002's edition of the same book he incorporated the notion of developing continuing bonds with the deceased (Klass et al., 1996), suggesting that individuals should have a connection with the person who is gone and at the same time be able to continue with their life. Worden's model seems more flexible because he recognised that the mourning experience can be different for each individual and that there are mediators that can affect the grief process. Furthermore, although Worden argued for specific mourning tasks that lead to an adjustment in life after loss, he also supported that "in a sense mourning is never finished" (Worden, 2009, p.77).

Bonanno and Kaltman (1999), supported that people may deal with grief in a cognitive way by applying coping strategies and in a social-functioning way by expressing positive emotions. Grief reactions are thus seen as similar to those that follow other negative life events.

Stroebe and Schut $(1999,2001)$ have also provided the Dual Process Model of mourning. Their model argues that there are loss-oriented stressors that are connected with the loss itself, like the ending of the physical relationship with the deceased and restorationoriented stressors that refer to the aftermath of loss and involve changed roles, changed 
relationships, and perhaps financial difficulties. Stroebe and Schut (1999) argued that there is an oscillation for the bereaved person between processing the loss and trying to restore his or her life. This oscillation aids successful coping. Stroebe and Schut's assumption "that it is not possible to attend to both dimensions at the same time" (Worden, 2009, p.53) was critiqued by Worden (2009) who supported that this notion is inflexible because people can actually grieve and at the same time try to restore their lives. Other bereavement theories (Marrone, 1999; Nerken, 1993; Schaefer \& Moos, 2003) focusing on the restorative aspect of grief, have described the grieving process as a journey of growth and personal development.

Although, task theories of mourning empowered individuals to "work through" their loss in order to adjust to an "after-loss" life -as is the case with stage theories- if they are taken literally and they are perceived as a linear process with a clear beginning and ending and if they are applied with a "must to" mentality they can add further distress to a person's mourning. Task theories should be flexible enough to give space for individuality and difference in the way that persons might manage with a loss and incorporate that loss in their life. Complicated grief and its subcategories of chronic grief, delayed grief, inhibited grief, absent grief, are concepts that can very easily apply to many people if we try to strictly fit the multifaceted and complex experience of loss within theories that attempt to universalise such a unique phenomenon in the form of stages or tasks that are the same for everyone. The concept of "healthy grieving" is proving increasingly inadequate in relation to the complexity and diversity of current Western society (Currer, 2001; as cited in Valentine, 2006). Wortman and Silver (1989) talked about "myths" that emerged from the grief literature. These myths conveyed that all who grieve are depressed, that those who don't grieve are susceptible to complicated grief, that work through the loss is a "must" and that eventually people recover from loss and bring a closure to grief. 


\section{A constructivist view}

In an attempt to create a theory which can encompass the complexity and the diversity of bereavement in people without pathologizing the cases that do not fit into the "universal" theories of grief and bereavement, constructivist psychologist Neimeyer (1998, 1999, 2000 2001) constructs or re-contructs the concept of grieving as a process of meaning with special emphasis on "its individuality rather than sameness across bereaved persons" (Neimeyer, 1999, p.66). Viewing mourning as a process of meaning reconstruction seems a much more flexible and "rich" approach since, whilst it acknowledges the role of the social context, it gives a stand to the idiosyncratic nature of the experience and asserts that the primary task for an individual is not to return to pre-loss functioning but to develop a meaningful life without the loved one (Wortman \& Silver, 2001). Attig (1996) has also conceptualised grieving as a process of "relearning" and further developing one's self-concept and life course.

\section{The theoretical concept of disenfranchised grief}

In order to complete this review of bereavement theories it seems mandatory to reference Doka's (1989) theoretical concept of disenfranchised grief. Almost all of the above theories dealt with death loss and losses that are for the most part socially recognised, acknowledged, sanctioned and "granted" with the right for grieving and mourning. Disenfranchised grief enables us to better understand the uniqueness, complexity and the importance of each individual loss experience that isn't recognised, legitimised, openly expressed and/or is pathologised, stigmatised or totally neglected (Doka, 1989). It acknowledges the fact that each loss must be recognised and validated.

More specifically, Doka (2002) suggested five broad categories of disenfranchised grief. The first one refers to losses in which the relationship is not recognised. This usually happens with non-kin relationships between lovers, friends, colleagues, therapists and clients, 
nurses and patients, and non-traditional relationships such as extramarital affairs and gay relationships. From all of the above examples it becomes evident that a great loss is any type of loss of a meaningful and significant attachment.

Another category refers to losses that are not acknowledged as socially significant (Doka, 2002). Abortions, divorces, relocations, placing children for adoption, loss of a companion animal may have a great psychological impact on the individuals who have experienced them. Furthermore, psychosocial deaths in which a person looses oneself due to mental illness or an organic syndrome such as Alzheimer disease may result in an immense loss that is not publicly acknowledged since no biological death occurs (Doka, 2002). This list becomes much longer when we include the loss of freedom, sexual vigour and any type of loss that may have a great impact on a person's psyche.

A third type of disenfranchised grief occurs when the griever is excluded because he or she is seen as "incapable" of grieving or "there is little or no recognition of his or her sense of loss and need to mourn" (Doka, 2002, p.13). In this case someone can think of children, old people, mentally ill or therapists who experience the death of a client.

The circumstances surrounding death may also lead to a disenfranchised grief since the family members of people who committed suicide or had AIDS or were sentenced to death become isolated in order to avoid the curiosity or even judgement of others (Doka, 2002).

Finally, even the way individuals grieve may lead to disenfranchisement (Doka, 2002). Persons who experience and express their loss without a strong affective response but in a more behavioural way by i.e. working long hours, are disenfranchised both by the counselling community (Martin \& Doka, 2000; Sue \& Sue, 1999) and the larger community. However, even the more intuitive people can be disenfranchised and labelled as chronic 
grievers after a period of time, since their emotional responses cease to seem appropriate (Martin \& Doka, 2000).

The above classification is not the only way to see disenfranchised grief and very rightly so Corr $(1998,2002)$ concludes that any significant loss might be disenfranchised in the way that it is experienced in terms of public and private grief responses and in terms of how the individual chooses to manage and live with that loss.

\section{Therapists' bereavement in the literature}

The breadth of therapists' bereavement in the literature is quite limited if one takes into account the importance of psychologists' well-being and personal development in their work with their clients. Chassen (1996) has also supported that a therapist's personal life has an impact on working with clients. A mental health practitioner's focus on the client probably contributes to neglecting the value of one's own experiences in what he or she will provide. However, some research and anecdotal papers have explored therapists' bereavement and loss experiences in different contexts. These were mainly therapists' experiences of the death of a close related kin, of the end of therapy due to clients' death, and of other types of personal losses (being seriously ill, losing a friend, losing a therapist and experiencing a divorce). Using these contexts this paper will explore the relevant literature.

\section{Therapists' experiences of the death of a close related kin}

Anecdotal accounts (Balsam \& Balsam, 1984; Givelber \& Simon, 1981; Guy, 1987; Rappaport, 2000; Shapiro, 1985; Ulman, 2001; Vamos, 1993) but also some qualitative research (Boyden, Bozenski, \& Colao-Vitolo, 2006; Millon, 1998), have all contributed to the 
exploration of the therapists' experience of the death of a close related kin and how it impacts the work with clients.

Some of the anecdotal accounts' authors talked about both positive and negative affects of their personal loss to client work. Givelber and Simon (1981), reflected on the experience of losing a close family member. They commented on how the professional role enhances the false idea that a therapist should manage better -a feeling that Rappaport (2000) also experienced- and how returning early to work can both negatively affect the therapeutic process by the therapist's resistances and also help one to be a more sensitive listener to loss related difficulties. Shapiro (1985), also mentioned how losing her mother due to cancer, presented opportunities but also dangers in her understanding and communication with one of her clients. Guy (1987), expressed his worries about many therapists returning to work while they still deal with their grief, however he also mentioned that grieving therapists might be more empathic with clients' emotional pain. In relation to the above, a survey by Hayes at al., (2007) which used 69 therapist-client dyads to extract data, showed that clients perceive their therapists as less empathic when they are still dealing with their loss and more empathic when they have resolved their grief. This research indicated that a therapist's unresolved losses may negatively affect the therapeutic process and pinpointed the importance of one being self-aware especially when the clients' difficulties are also loss related. Rosenberg and Hayes (2002), have also showed in their case study that when therapists' unresolved issues are touched in therapy, avoidance behaviour and disruption of the working alliance may occur.

Other authors presented their personal accounts describing negative aspects of working with clients after experiencing a death in the family. Vamos (1993), argued that after losing her husband, working with clients was very hard and that disclosing or not, probably depended on her own difficulties and not her therapeutic considerations. On this note, Tsai, 
Plummer, Kanter, Newring and Kohlenberg (2010), using data from questionnaires that were sent to one of the author's clients, noted that self-disclosure can be of great therapeutic value since it can open a door to feelings, relationships and themes that were previously unexplored. However, the decision of not disclosing or disclosing and to what degree, must be made after taking into account the uniqueness of the personality of each client, his or her issues and the therapeutic relationship. Rappaport (2000) also expressed how after her loss she was more impatient and irritated with her clients due to her vulnerability. Furthermore, Balsam and Balsam (1984) supported that the returning clinicians might not be capable to engage well since due to their loss, they may "see loss" in everything the client brings. Ulman (2001), using a case example, showed how a bereaved therapist lost his ability to be self-aware and self-reflective. The experience of grieving and working at the same time was also brought to the big screen by director Nanni Morreti in 2001, with his Cannes awarded movie, entitled The son's room.

Although loss is quite a rich, complex phenomenon and can be a unique experience for each individual, only two qualitative studies (Boyden et al., 2006; Millon, 1998), both dissertations, have explored the therapists' loss experiences of a close related kin and how these affected the psychotherapeutic process.

Millon (1998) interviewed ten psychodynamic therapists who had lost a significant family member six months to seven years prior to the interview. The participants' responses were organised into four themes: expectations regarding the grieving process, self-disclosure, impact of grief on therapeutic work, and on the therapist's identity. Participants complained about the naïve others in their lives that simplified their grief. Probably their grief experience was disenfranchised by their environment and preconceived notions of how their grief might be. They also reported having a continuing internal relationship with the deceased (Klass et al., 1996) . Self-disclosure varied among the participants and their stance was mostly affected 
by how experienced they were and how they thought that their self-disclosure would affect the client. Their psychodynamic orientation seemed to play a lesser role in their decision to disclose or not. Three psychotherapists talked about an indirect form of disclosure, in which they would feel that their clients could perceive their altered emotional state and general presence in the therapy room. The interviewees reported that they found some comfort in the structure of their work (Givelber \& Simon, 1981) however, they also mentioned that their emotional state was unstable and at times it would interfere with providing therapy. This relates to the previously mentioned findings of how unresolved losses and issues may have a negative impact in the therapeutic process (Hayes et al., 2007; Rosenberg \& Hayes, 2002). More specifically, participants talked about being more vulnerable and emotionally sensitive. This could result in them being at times more empathic with clients and other times less attuned to what the clients were saying. They were preoccupied more with their own loss rather than the client's experience. This could lead to feelings of resentment and irritability towards clients (Rappaport, 2000) as well as a tendency to get support from them. Participants also stated that their experience changed them in terms of realising their own mortality, having an increased awareness of death, grief, loneliness, how little control one has over life and how an element of pain will always be present (Worden, 2009).

Millon's research (1998) was valuable it terms of being the first qualitative study to address such an important topic that has a great impact both on the therapists' personal and professional life. However, there were some faults that seem to affect its credibility. Millon stated that she used a qualitative semi-structured interview question design but she didn't mention her ontology, epistemological stance, the specific qualitative method that she used, how she went through with her analysis and how her own experience of losing someone as a therapist affected her study. Finally, although Millon states that her study examines the therapists' experience of a major loss through death, by interviewing only therapists who lost 
a family member she limited the meaning of "major loss through death" since she excluded non-kin but very intimate attachment relationships, and in this way she colluded with the disenfranchisement of these losses.

Boyden (2006), Bozenski (2006) and Colao-Vitolo (2006) conducted a collaborative qualitative research study on psychologist bereavement and its impact on the psychotherapy process for their thesis. All the dissertations commented on the general aspects of bereavement and each one of them explored a different aspect that related to the psychotherapeutic process, namely, coping with bereavement, shifts in empathy and selfdisclosure. The qualitative method used was CQR (Consensual Qualitative Research) (Hill, Thompson \& Williams, 1997). Twelve psychologists were recruited using a chain of referral method and were telephone interviewed. In terms of the general aspects of psychologist's bereavement, therapists typically reported a continuing bond with the deceased, suggesting that this may be an adaptive way of coping with loss. Others (Davies, 2004; Klass et al., 1996; Walter, 1996, 1999; Worden, 1991, 2002, 2009) have also supported this. Furthermore, psychologists experienced the death of their loved one as unexpected, regardless of whether they cognitively expected the death or not. The primarily emotional reaction to death was sadness. The participants talked about both their current loss and past losses indicating that grief is not a linear process with a "clear cut end". Other theorists (Corr, 1998, 2002; Doka, 2002; Wortman \& Silver, 1989; Worden, 2009) have also implied or asserted this. Finally, psychologists reported experiencing a change of perspective in life that was affected by a heightened awareness of their own and others mortality (Millon, 1998).

In terms of psychologists' coping, Colao-Vitolo (2006) noted that the participants reported finding a variety of coping methods useful namely, talking, socializing, and connecting with family. It seems that social support is of great importance (Doka, 2002; Sanders, 1989; Worden, 2009). They also reached out for professional guidance indicating 
that supervision and personal therapy can be of great help (Henderson, 2005; Mahoney, 1997). Involvement in funeral services, (Rando, 1984), creative expressions (i.e. music), selfreflection (Muller \& Thompson, 2003) and seeing clients (Givelber \& Simon, 1981) were also seen as helpful. However, interviewees also reported that they experienced hindrances in their coping when others didn't understand their grief (Millon, 1998). It seems that disenfranchised grief (Doka, 1989) can also be experienced by people who have lost a close family member. Finally, they reported that looking back, things that they would have done differently would be spending more time with the family, the deceased and taking more time off work.

In terms of empathy, Bozenski (2006) found that psychologists felt increased empathy for clients after the death of a loved one, something that Givelber and Simon (1981) and Guy (1987) also reported in their anecdotal accounts. More specifically, participants stated that they had a deeper connection and understanding of their clients, as well as increased sensitivity to their clients' experiences of grief and loss. However, irritability with clients (Rappaport, 2000) and emotional instability (Millon, 1998) were also reported. The psychotherapists also mentioned that their loss made their clients more empathic towards them. In general, the interviewees expressed that their increased empathy informed their therapeutic interventions. These results suggest that although bereavement might be a very challenging experience it could also result to increased empathy and deep communication with the clients.

Finally, Boyden (2006) explored the impact of therapists' bereavement on selfdisclosure and found that psychologists usually disclose their loss to one or more clients. The type and amount of disclosure varied from client to client and depended on the length of time clients had been to therapy. In relation to this, Myers and Hayes (2006) conducted an analogue study which showed that disclosure can be quite positive but only when the client 
perceives the working alliance to be strong. Boyden (2006), also reported that disclosure was affected by whether the clients were having loss issues themselves, therapists' theoretical orientation, cultural factors and finally, whether the clients posed a question to the therapists about their absence. Most of the psychologists believed that their disclosure was beneficial for the therapeutic relationship.

The above collaborative qualitative study from Boyden (2006), Bozenski (2006), and Colao-Vitolo (2006), made a notable contribution to the under researched area of therapists' bereavement and its impact on working with clients. It drew attention to the implications of therapists' bereavement to practice, paving the way for more research in this area. Furthermore, the interview process itself possibly resulted in increased self-awareness and insight for the therapists, qualities that are always beneficial for clinical practice.

However, there are some aspects of this study that call for further attention. This research mainly explored parental losses thus major non-kin losses were once again disenfranchised. The application of the CQR method seemed faithful to its guidelines (Hill, Thompson \& Williams, 1997) however, I wonder if the use of a qualitative method, like IPA (Interpretative Phenomenological Analysis), that gives space for more interpretation of the findings would have been more appropriate for this research topic.

The interviews were conducted over the phone and although the researchers found this facilitating for the extraction of information -since it was a very personal and sensitive topic-, I have the impression that due to the lack of face to face contact and intimacy between the interviewers and the interviewees non-verbal messages and communication were possibly lost. Lastly, although there was a very good reference on bereavement theories and relevant literature, it wasn't used adequately for a more holistic and reflective presentation of the results.

\section{Therapists' experiences of clients' death}


The end of therapy due to a clients' death can be a major event in the personal and professional life of the therapist. The existing literature has explored the areas of therapists' experiences of clients' suicide and of multiple deaths due to terminal illnesses, however there is paucity in the research of non-suicidal clients who suddenly died. In this paper more attention will be paid in the later category due to the fact that is under researched although of great importance since the psychologists' grief in this case seems to be more disenfranchised not only by the research community but also by the working and social environment and academic training.

Therapists who experience a client's suicide are affected both as individuals who may have lost a significant other but also as professionals who have experienced a crisis in their work (Horn, 1994). This usually results in intense and conflicting feelings of shock, disbelief, sadness, anger towards the client, fear of blame, and feelings of guilt or professional incompetence (Alexander, 2007; Cotton, Drake, Whitaker \& Potter 1983; Hendin, Lipschitz, Maltsberger, Pollinger, \& Wynecoop, 2000; Kleespies, Smith \& Becker, 1990; Valente, 1994). The "surviving" therapist seems to experience emotions that resemble the stage theories of grief. Emotional acceptance and resolution have been described by Carter (1971) and Cotton et al. (1983) as the "final stage" for "surviving" therapists of suicide. However, it seems that the grieving process may not have a clear end (Stern, 1986) and that therapists' grief depends on the quality of the relationship with the client (Christianson \& Everall, 2009). Several surveys found that the impact of suicide is greater on trainees (Kleespies, Penk \& Forsyth, 1993; McAdams \& Foster, 2000), that the therapists may experience intense distress and grief (Chemtob, Hamada, Bauer, Kinney, \& Torigoe, 1988; Dewar, Eagles, Klein, Gray, \& Alexander, 2000; Goldstein \& Buongiono, 1984; Hendin et al., 2000; Kleespies et al., 1990; McAdams \& Foster, 2000), they may become very cautious with suicidal clients (Dewar et al. 2000; McAdams \& Foster, 2000) and even stop working with them (Hendin et 
al., 2000). Conversely, getting support from supervisors, colleagues, personal therapy, family, friends (Goldstein \& Buongiono, 1984; Ruskin, Sakinofsky, Bagby, Dickens, \& Sousa, 2004), talking to the deceased's relatives and attending the funeral (Hendin et al., 2000; Kleespies et al., 1990; McAdams \& Foster, 2002) were reported as being very helpful. Support for mental health practitioners who are survivors of clients' suicide is available in many work contexts however, many therapists work in private practice and might not have this kind of support. The lack of qualitative research calls for studies that can capture in a more encompassing, flexible and explorative way the losses and struggles of the therapists who have experienced a client suicide. This will help to draw more attention since although, mental health professionals are beginning to receive recognition as legitimate survivors (Grad and Michael, 2005), there seem to be a long road ahead.

Dealing with multiple clients' deaths due to terminal illness can greatly impact the personal and professional lives of mental health practitioners. Empirical studies (Allen \& Miller, 1988; Bennet, Kelaher \& Ross, 1994; Hunt \& Rosenthal, 2000; Kachik, 2001), clinical vignettes (Gabriel, 1991; Strug \& Podell, 2002), personal accounts (Bell, 1988) and the works of Bennet (1995), Dane (1995), Dane and Miller (1992), and Katz and Johnson, (2006) support that therapists experience grief, depression, helplessness, battle fatigue syndrome, while Post Traumatic Stress Disorder (Gabriel, 1994), inability to treat future patients (Bonde, 2001) but also greater empathy towards clients after such experiences (Allen \& Miller, 1988) have also been reported. On this note, Worden (2009) has suggested three guidelines to help mental health practitioners who work with dying individuals. The first is for therapists to know their limitations in terms of how many persons at any given point in time they can have a close relationship and work with. Secondly, Worden argued that psychotherapists should actively grieve and let themselves experience their personal feelings without suppressing them. Finally, he asserted that all therapists should get support from their 
professional and personal contexts. Mental health practitioners who deal with multiple deaths usually work within institutional settings that provide training and support in the form of workshops, supervision, group discussions and institutional rituals. Furthermore, these deaths usually are anticipated and part of the therapeutic work is to reflect on unresolved issues and prepare one to say "good-bye". But what happens with therapists who don't work in such contexts and don't anticipate a client's death?

Research on clients' death in these circumstances is almost inexistent. Anecdotal papers (Buechler, 2000; Levinson, 1972) comment on therapists' experiences of grieving, feeling pain, having difficulty working with future clients and not being able to talk to others who knew the client and share their feelings. Their sadness was characterised by isolation since due to their professional role and relationship with the deceased their feelings were seen as "unacceptable" (Doka, 1989). Their disenfranchised grief (Doka, 1989), intensified the impact of their experience in their personal and professional lives. Even if the end of the therapeutic relationship isn't due to a client's death, nevertheless, therapists may experience a significant loss of a relationship (Goodyear, 1981) especially if this relationship was a long, intimate and productive one.

The only empirical research on therapists' experiences of client sudden death is Schwartz's (2004) qualitative study that was conducted for her thesis. Schwartz (2004) used in-depth semi-structured interviews for her nine participants. Schwartz concluded in five meta-themes namely, attachment in the therapeutic relationship, therapist's bereavement, therapist left holding the bag, coping with client sudden death and lessons learned.

The author argued that if during treatment an attachment develops with the client then the therapist experiences feelings of bereavement. The significance of the attachment relationship has also been pinpointed by theorists like Bowlby $(1961,1973,1980)$, Doka (2002), Fraley and Shaver (1999), Parkes (2001), Shaver and Tancredy (2001), and Worden 
(2009). Schwartz concluded that the therapists' bereavement had similarities but also differences with other theories of bereavement that were generated from Bonanno and Kaltman (1999), Rando (1993), Saunders (1989), Stroebe and Stroebe (1987), and Worden (1991). The therapists' bereavement was also influenced by their spiritual beliefs, professional role and other concurrent crises in their life. As other authors noted, the professional role can inhibit and isolate a therapist's grief (Buechler, 2000; Doka, 2002; Rubel, 2004). Due to the intimacy of the therapeutic relationship and the knowledge of clients' private thoughts some therapists experienced the feeling of "being left holding the bag", that emerged from knowing their clients' unfinished business. Things that helped them cope was receiving social support (Doka, 2002; Sanders, 1989; Worden, 2009), attending rituals (Rando, 1984), or creating personal rituals (Doka, 2002), and maintaining a connection with the deceased (Klass et al., 1996; Walter, 1996, 1999; Worden, 1991, 2002, 2009). However, participants also noted that they felt that their grief was disenfranchised by themselves due to their professional role and relationship with the client and by others in their social and working environment, adding that prior training in losing a client could have been helpful.

A client's death affected their work in diverse ways and participants reported feeling more attuned and genuine with the clients (Allen \& Miller, 1988; Givelber \& Simon, 1981; Guy, 1987), feeling more pressured to address some issues in the therapeutic relationship but also feeling less able to tolerate negative and self-harming behaviour from clients (Rappaport, 2000), and having difficulty to form attachments with future clients. In terms of personal impact interviewees reported an increased awareness of mortality and existential issues (Boyden et al., 2006; Millon, 1998), but also a normalisation of their feelings and need to grieve. 
Schwartz's (2004) pioneer study contributed to the "enfranchisement" of therapists' grief after experiencing the death of a client. Participants reported that the interview process itself made them more aware of their feelings and of the event's impact on their personal and professional life. This study offered a thorough look at the under researched area of losing a client to sudden death and by doing so, it gave voice to the uniqueness of such an experience and the multiple ways it can affect the therapist as a person and as a professional. It drew attention to the importance of acknowledging such experiences and providing support and training in order to enhance personal development and therapeutic practice.

However, in terms of the way the research was conducted there are some aspects that call for further attention. There was extensive use of grief literature in relation to the findings and very successfully Doka's concept of disenfranchised grief was also used to describe the therapists' loss however, maybe the grief theory context in which the findings where presented would have been more complete with the addition of a more constructivist theory (Neimeyer, 1998, 1999, 2000, 2001). Finally, although the author gave a lively description of each participant and his or her experiences, the findings were presented as a list of themes and maybe a presentation in a narrative form would have been more appropriate.

\section{Other types of therapists' personal losses}

Using Doka's $(1989,2002)$ theoretical concept of disenfranchised grief, other significant losses in the therapist's life that received limited attention by the research community will be explored, given the impact they may have on the mental health practitioners' psychological functioning and work with clients.

Loss of health may not be seen as a significant loss because one is still physically present whatever the illness implications to the self might be. Wong (1990) commented on her own illness and its meanings reporting a loss of her body as she knew it, of her control 
over herself, of her competence and reasoning. Therapists' defences such as denial, omnipotence, narcissistic withdrawal and reaction formation against weakness (Bram, 1995; Chernin, 1976; Counselman \& Alonso, 1993; Dewald, 1994; Halpert, 1982) may cause great harm to the neutrality, objectivity, empathy and general engagement with the client (Counselman \& Alonso, 1993; Halpert, 1982). A therapist's unresolved losses may affect negatively the therapeutic process as any other unresolved issues (Hayes et al., 2007). From the above, it becomes evident that if therapists acknowledge and "work through" their loss of health and own mortality, then their therapeutic practice can develop and improve. Sharing her personal experience Morrison (1990) stated: "I often felt that I was able to listen with a 'fourth' ear, particularly for issues of loss..." (p.229) and "The experience informs my life. I postpone things less; I try to live more fully. I think this attitude infused my work. I feel both freer and more fully 'there' with patients" (p.246).

Of course therapists can be clients as well, and thus witness and experience the illness and death of their psychotherapists. As Fowlkes (1989) noted, this grief is probably isolated since it isn't socially sanctioned. Garfield (1990) shared his experience of losing his analyst and how this resulted to feelings of anger, sadness, guilt, and being lost without knowing it because he didn't realise he was grieving. Due to the type of relationship between Garfield and his analyst, this loss was disenfranchised not only by his social context but also by himself. Rendely (1999) also shared her own loss of her analyst due to cancer and called for recognition of the grieving analysands and their right to mourn their loss. Another instance of disenfranchised loss was Lewis's (1982) anecdotal paper on his experience of loosing four friends and ending up denying any affect. His denial greatly affected his psychotherapeutic competence. Pappas (1989) commented on her disenfranchised loss of divorce. A loss that is not acknowledged because although a relationship ends it is not due to death and it is seen as the resolution of a troubled period in someone's life. Pappas viewed her divorce as a 
significant loss and she went through a grieving process. She reported that working through her loss improved her practice with persons who were presenting loss issues.

All of the above anecdotal papers reported significant personal losses indicating their capacity for deleterious but also regenerating affects on a personal and professional dimension. Worden (2009) argues that exploring one's own history of losses makes one a more effective therapist. Before doing this, one should also ask oneself: What are my personal losses and how have these affected me and continue to affect me? Qualitative research can open a key door to this exploration of such a significant but unexplored area of personal and professional growth.

\section{Discussion}

This paper reviewed the literature on therapists' bereavement and loss experiences. The existing bereavement theories and the relevant studies on therapists' experiences of the death of a close related kin, of the death of a client and of other significant personal losses were used as a framework in order to give a panoramic view of a neglected but ever present and life transforming theme in mental health practitioners' lives. By doing so, it pinpointed the multiple ways in which a significant loss may affect one's personal well-being, development and clinical practice. Thus, it is hoped that it will draw more attention from the academic and clinical community for further contribution and exploration since up till now, the relevant research is limited. It seems that one of the aims of future research should be the "enfranchisement" of this disenfranchised researched topic.

Disenfranchisement took the form of lack of exploration of other types of losses in the literature but also coloured therapists' bereavement due to the death of a close family member (Boyden, Bozenski, Colao-Vitolo, 2006; Millon, 1998). Participants?? complained about the naïve others in their lives that simplified their grief due to preconceived notions of how their 
grief might be (Millon, 1998). This resulted in experiencing hindrances in their coping (Colao-Vitolo, 2006). Furthermore, it was evident in cases where mental health practitioners had experienced the death of a client (Buechler, 2000; Levinson, 1972; Rubel, 2004, Schwartz 2004). In this context their professional role and relationship with the client inhibited the processing of their possible loss and enchased their isolation not only due to the social and working environment's disenfranchisement but also to self-disenfranchisement (Kauffman, 2002). The presentation of other significant personal losses indicated how the acknowledgement, recognition and reflection on such experiences can be beneficial not only to personal growth but also clinical practice.

The need for further research seems even greater in the cases where a significant loss experience is disenfranchised since in these instances there is repression of grief emotions and behaviours, isolation and confusion. As Doka (2002) noted: "the very nature of disenfranchised grief creates additional problems for grievers while removing or minimising their sources of support”, (p. 17).

This review showed that significant personal losses have a great impact on a personal and professional dimension. But who determines for whom which loss can be "significant"? Up till now the research that has been conducted explored specifically the loss of a kin or of a client. I believe that more "space" should be given to participants to also express other possible personal loss experiences that can be of great importance and meaning in terms of the impact of that loss on the self but also in the work with clients. This way not only the scope of the meaning of "loss" is broadened and the disenfranchisement is limited but also the possible idiosyncratic importance and impact of a loss experience for each individual is recognised.

There is a folk wisdom that therapists can only go as far into the emotional depths of their clients as they have gone themselves. It seems that where there is a lack of recognition 
and acknowledgement there also lies the greater potential for growth and development. For this reason the exploration of two research questions is of particular interest: 1 . How therapists' experiences of loss may affect them personally and professionally? The purpose of the broadness of this question is to give space for the inclusion of loss experiences that the participants themselves find personally significant; and, 2. How therapists' possible disenfranchisement experiences of their losses may affect them personally and professionally? It is hoped that by this endeavour more awareness and insight may result not only for the research participants but also for the academic and especially the psychotherapeutic community and its services to clients. Self-reflection is deemed as one of the most powerful "tools" in a psychotherapist's personal and professional development. The disenfranchised theme of therapists' loss experiences may offer the most fruitful ground for such growth. 


\section{References}

Alexander, J. L. (2007). Client suicide: This is not happening to me: A clinical report and personal memoir. Smith College Studies in Social Work, 77 (2/3), 67-79.

Allen, H. A., \& Miller, D. M. (1988). Client death: A national survey of the experiences of certified rehabilitation counselors. Rehabilitation Counseling Bulletin, 32 (1), 58-64.

Attig, T. (1996). How we grieve: Relearning the world. New York: Oxford University Press.

Balsam, R. M., \& Balsam, A. (1984). Becoming a psychotherapist: A clinical primer (2nd Ed.). Chicago: University of Chicago Press.

Barbagallo, A. (Producer), Fabrizio, F. (Producer), Galuzzo, V. (Producer), \& Moretti N. (Director). (2001). The son's room [Motion picture]. Italy: Sacher Film

Bell, J. P. (1988). AIDS and the hidden epidemic of grief: A personal experience. American Journal of Hospice Care, 5, 25-31.

Bennet, L. (1995). Aids health care: Staff stress, loss and bereavement. In Sherr, L. (Ed.), Grief and AIDS (pp. 87-102). New York: John Wiley \& Sons.

Bennet, L., Kelaher, M., \& Ross, M. W. (1994). The impact of working with HIV/AIDS on health care professionals: Development of the AIDS impact scale. Psychology and Health, 9, 221-232.

Beutler, L. E., Malik, M., Alimohamed, S., Harwood, T. M., Talebi, H., Noble, S., \& Wong, E. (2004). Therapist variables. In M. J. Lambert (Ed.), Bergin and Garfield's handbook of psychotherapy and behavior change (5th ed., pp. 227-306). New York: Wiley.

Bonanno, G. A., \& Kaltman, S. (1999). Toward an integrative perspective on bereavement. Psychological Bulletin, 125, 770-776.

Bonde, L. (2001). The effects of grief and loss on decision making in HIV-related psychotherapy. In Anderson J. R., \& Barret (Eds.), Ethics in HIV-related 
psychotherapy: Clinical decision making in complex cases (pp. 83-98). Washington, DC: American Psychological Association.

Bowlby, J. (1961). Processes of mourning. International Journal of Psychoanalysis, 39, 350373.

Bowlby, J. (1973). Attachment \& loss: Vol. 2. Separation: Anxiety and anger. London: Hogarth Press \& Institute of Psychoanalysis.

Bowlby, J. (1980). Attachment \& loss: Vol. 3. Loss: Sadness and depression. London: Hogarth Press \& Institute of Psychoanalysis.

Boyden, S. (2006). Psychologist bereavement and self-disclosure: Impact on the therapeutic process (Doctoral dissertation). Retrieved from ProQuest Dissertations and Theses Database, (UMI No. 3203156).

Bozenski, J. (2006). The impact of bereavement on empathy in psychotherapy. (Doctoral dissertation). Retrieved from ProQuest Dissertations and Theses Database, (UMI No. $3218515)$.

Brabant S. (2002). A closer look at Doka's grieving rules. In Doka, K. J. (Ed.), Disenfranchised grief. New directions, challenges, and strategies for practice. (pp. 2338). Champaign, IL: Research Press.

Bram, A. D. (1995). The physically ill or dying psychotherapist: A review of ethical and clinical considerations. Psychotherapy, 32 (4), 568-580.

Buechler, S. (2000). Necessary and unnecessary losses. Contemporary Psychoanalysis, 36 (1), 77-90.

Carter, R. E. (1971). Some effects of client suicide on the therapist. Psychotherapy: Theory, Research and Practice, 8 (4), 287-289. 
Chassen, B. (1996). Death of a psychoanalyst's child. In Barbara Gersen (Ed.) The therapist as a person: life crises, life choices, life experiences, and their effects on treatment (pp. 3-20). Hillsdale, NJ: The analytic Press.

Chemtob, C. M., Hamada, R. S., Bauer, G., Kinney, B., \& Torigoe R. Y. (1988). Patient's suicides: Frequency and impact on psychiatrists. American Journal of Psychiatry, 145, 224-228.

Chernin, P. (1976). Illness in a therapist: Loss of omnipotence. Archives of General Psychiatry, 33 (11), 1327-1328.

Christianson, C. L., \& Everall, R. D. (2009). Breaking the silence: School counsellor's experiences of client suicide. British Journal of Guidance \& Counselling. 37 (2), $157-$ 168.

Colao-Vitolo, N. (2006). Coping and bereaved psychologists: Impact on the psychotherapy process. (Doctoral dissertation). Retrieved from ProQuest Dissertations and Theses Database, (UMI No. 3218517).

Cook, A. S., \& Dworkin, D. S. (1992). Helping the bereaved: Therapeutic interventions for children, adolescents, and adults. New York: Basic Books.

Corr, C. A. (1993). Coping with dying: Lessons that we should and should not learn from the work of Elizabeth Kubler-Ross. Death Studies, 17, 69-83.

Corr, C. A. (1998). Enhancing the concept of disenfranchised grief. Omega, 38, 1-20.

Corr, C. A. (2002). Revisiting the concept of disenfranchised grief. In Doka, K. J. (Ed.), Disenfranchised grief. New directions, challenges, and strategies for practice. (pp. 3960). Champaign, IL: Research Press.

Corr, C. A., Nabe, C. M., \& Corr, D. M. (2000). Death and dying, life and living, (3 ${ }^{\text {rd }}$, ed.). Belmont, CA: Wadsworth. 
Cotton, P. G., Drake, R. E., Whitaker, A., \& Potter, J. (1983). Dealing with suicide on a psychiatric inpatient unit. Hospital and Community Psychiatry, 34 (1), 55-58.

Counselman, E. F., \& Alonso, A. (1993). The ill therapist: Therapist's reactions to personal illness and its impact on psychotherapy. American Journal of Psychotherapy, 47, 591602.

Dane, B. O. (1995). Overcoming grief associated with caring for AIDS patients. In Odets, W. \& Shernoff, M. (Eds.),The second decade of AIDS: A mental health practice book (pp. 275-291). New York: Hatherleigh Press.

Dane, B. O., \& Miller, S. O. (1992). AIDS : Intervening with hidden grievers. Wesstpot, CT: Auburn House.

Davies, R. (2004). New understandings of parental grief: Literature review. Journal of Advanced Nursing, 46, 506-512.

Dewald P. A. (1994). Countertransference issues when the therapist is ill or disabled. American Journal of Psychotherapy, 48, 221-226.

Dewar, I., Eagles, J., Klein, S., Gray, N., \& Alexander, D. (2000). Psychiatric trainees experiences of, and reactions to, patient suicide. Psychiatric Bulletin, 24, 20-23.

Doka, K. J. (Ed.), (1989). Disenfranchised grief: Recognizing hidden sorrow. Lexington, MA: Lexington.

Doka, K. J. (Ed.), (2002). Disenfranchised grief. New directions, challenges, and strategies for practice. Champaign, IL: Research Press.

Fowlkes, M. (1989). The morality of loss: The social construction of mourning. Presented at the annual meeting of the American Sociological Association, San Francisco.

Fraley, R. C., \& Shaver, P. R. (1999). Loss and bereavement: Attachment theory and recent controversies concerning "grief work" and the nature of detachment. In Cassidy, J. \& 
Shaver, P. R. (Eds.) Handbook of attachment: Theory, research and clinical applications (pp. 735-759). New York: Guilford.

Freud, S. (1957). Mourning and Melancholia. In J. Stranchey (Ed. \& Trans.), The standard edition of the complete psychological works of Sigmund Freud (Vol. 14, pp.239-260). London: Hogarth Press \& Institute of Psychoanalysis (Original work published 1917).

Gabriel, M. A. (1991). Group therapists' countertransference reactions to multiple deaths from AIDS. Clinical Social Work Journal, 19 (3), 279-292.

Gabriel, M.A. (1994). Group therapists and AIDS groups: An exploration of traumatic stress reactions. Group, 18 (3), 167-176.

Garfield, D. A. S. (1990). Manifestations of grief and grievance: A therapist's response to an analyst's death. In Schwartz, H. J, \& Silver, A. S. (Eds.), Illness in the analyst: implications for the treatment relationship (pp. 253-266). Madison, CT, US: International Universities Press.

Givelber, F., \& Simon, B. (1981). A death in the life of a therapist and its impact on therapy. Psychiatry, 44, 141-149.

Goldstein, L. S., \& Buongiorno, P. A. (1984). Psychotherapists as suicide survivors. American Journal of Psychotherapy, 38, 392-398.

Goodyear, R. K. (1981). Relationship loss: Termination as a loss experience for the counsellor. The Personnel and Guidance Journal, 59, 347-350.

Grad, O.T., \& Michel, K. (2005). Therapists as client suicide survivors. Women \& Therapy, $28,71-81$.

Guy, J. D. (1987). The personal life of the psychotherapist. New York: John Wiley \& Sons.

Halpert, E. (1982). When the analyst is chronically ill or dying. Psychoanalytic Quarterly, 51 (3), 372-389. 
Hayes, J. A., Yeh, Y., \& Eisenberg, A. (2007). Good grief and not so good grief: Countertransference in bereavement therapy. Journal of Clinical Psychology, 63 (4), $345-355$.

Henderson, P. (2005). Bereavement and the supervisory relationship. Therapy Today, 16 (7), $30-32$.

Hendin, H., Lipschitz, A., Maltsberger, J. T., Pollinger Haas, A., \& Wynecoop S. (2000). Therapists' reactions to patients' suicides. American Journal of Psychiatry, 157, 20222027.

Hill, C., Thompson, B., \& Williams E. (1997). A guide to contacting consensual qualitative research. Counseling Psychologist, 25, 517-572.

Horn, P. J. (1994). Therapists' psychological adaptation to client suicide. Psychotherapy, 31, 190-195.

Hunt, B., \& Rosenthal, D. A. (2000). Rehabilitation counselor's experiences with client death and death anxiety. The Journal of Rehabilitation, 66 (4), 44-50.

Kachik, J. R. (2001). Reactions of mental health professionals to the death of clients from acquired immune deficiency syndrome (AIDS). Dissertations Abstracts International, 62(1-B), 551.

Katz, R., \& Johnson, T. (2006). When professionals weep: Emotional and countertransference responses in end-of-life care. New York: Routledge.

Kauffman J. (2002). The psychology of disenfranchised grief: Liberation, shame, and selfdisenfranchisement. In Doka, K. J. (Ed.), Disenfranchised grief. New directions, challenges, and strategies for practice. (pp. 61-77). Champaign, IL: Research Press.

Klass, D., Silverman, P. R., \& Nickman, S. (Eds.). (1996). Continuing bonds: New understandings of grief. Washington, DC: Taylor \& Francis. 
Kleespies, P. M., Penk, W. E., \& Forsyth, J. P. (1993). The stress of patient suicidal behavior during clinical training: Incidence, impact, and recovery. Professional Psychology Research and Practice, 24 (3), 293-303.

Kleespies, P. M., Smith, M. R., \& Becker, B. R. (1990). Psychology interns as patient suicide survivors: Incidence, impact, and recovery. Professional Psychology Research and Practice, 21 (4), 257-263.

Kübler-Ross, E. (1969). On death and dying. New York: Macmillan.

Levinson, P. (1972). On sudden death. Psychiatry, 35, 160-173.

Lewis, J. M. (1982). Dying with friends: Implications for the psychotherapist. The American Journal of Psychiatry, 139 (3), 261-266.

Mahoney, M. J. (1997). Psychologists' personal problems and self-care patterns. Professional Psychology: Research and Practice, 28(1), 14-25.

Marrone, R. (1999). Dying, mourning, and spirituality: A psychological perspective. Death Studies, 23, 495-519.

Martin, T. L., \& Doka, K. J. (2000). Men don't cry . . . women do: Transcending gender stereotypes of grief. Philadelphia: Brunel/Mazel.

McAdams, C.R., \& Foster, V.A. (2000). Client suicide: Its frequency and impact on counselors. Journal of Mental Health Counseling, 22 (2), 107-121.

McAdams, C.R., \& Foster, V.A. (2002). An assessment of resources for counselor coping and recovery in the aftermath of client suicide. Journal of Humanistic Counseling, Education and Development, 41, 232-240.

Millon, M. L., (1998). Death in life: The impact of major loss on the therapist's work. (Doctoral dissertation). Retrieved from ProQuest Dissertations and Theses Database, (UMI No. 9832075). 
Morrison, A. L. (1990). Doing psychotherapy while living with a life-threatening illness. In Schwartz, H. J, \& Silver, A. S. (Eds.), Illness in the analyst: implications for the treatment relationship (pp. 227-250). Madison, CT, US: International Universities Press.

Muller, E. D., \& Thompson, C. L. (2003). The experience of grief after bereavement: A phenomenological study with implications for mental health counseling. Journal of Mental Health Counseling, 25 (3), 183-203.

Myers, D., \& Hayes, J. A. (2006). Effects of therapist general self-disclosure and countertransference disclosure on ratings of the therapist and session. Psychotherapy, $43,173-185$.

Neimeyer, R. A. (1998). Lessons of loss. A guide to coping. New York: McGraw-Hill.

Neimeyer, R. A. (1999). Narrative strategies in grief therapy. Journal of Constructivist Psychology, 12, 65-85.

Neimeyer, R. A. (2000). Searching for the meaning of meaning: Grief therapy and the process of reconstruction. Death Studies, 24, 541-558.

Neimeyer, R. A. (2001). The language of loss: Grief therapy as a process of meaning reconstruction. In Neimeyer, R. A. (Ed.), Meaning reconstruction and the experience of loss (pp. 26-292). Washington, DC: American Psychological Association.

Nerken, I. R. (1993). Grief and the reflective self: Toward a clearer model of loss resolution and growth. Death Studies, 17, 1-26.

Pappas, P. A. (1989). Divorce and the psychotherapist. American Journal of Psychotherapy, $43,506-517$.

Parkes, C. M. (1972). Bereavement: Studies of grief in adult life. New York: International University Press. 
Parkes, C. M. (2001). A historical overview of the scientific study of bereavement. In Stroebe M. S., Hansson R. O., Schut H., \& Stroebe W. (Eds.). Handbook of Bereavement Research: Consequences, coping, and care (pp. 25-45). Washigton, DC: American Psychological Association.

Parkes, C. M. \& Weiss, R. S. (1983). Recovery from bereavement. New York: Basic.

Rando, T. A. (1984). Grief, dying, and death: Clinical interventions for caregivers. Champaign, IL: Research Press.

Rando, T. A. (1993). Treatment of complicated mourning. Champaign, IL: Research Press.

Rando, T. A. (1995). Grief and mourning: Accommodating to loss. In Wass H., \& Neimeyer R. A. (Eds.), Dying: Facing the facts (pp. 211-241). Washington, DC: Taylor \& Francis.

Raphael, B. (1984). The anatomy of bereavement: A handbook for the caring professions. London: Hutchinson.

Rappaport, J. (2000). Traumatic time: The therapist's mourning. Psychoanalysis and Psychotherapy: The Journal of the Postgraduate Center for Mental Health, 17, 55-64.

Rendely, J. (1999). The death of an analyst: The loss of a real relationship. Contemporary Psychoanalysis, 35 (1), 131-152.

Rosenberger, E. W., \& Hayes, J. A. (2002). Origins, consequences, and management of countertransference: A case study. Journal of Counseling Psychology, 49, 221-232.

Rubel, R. (2004). When a client dies. Psychoanalytic Social Work, 11 (1), 1-14.

Ruskin, R., Sakinofsky, I., Bagby, R. M., Dickens, S., \& Sousa, G. (2004). Impact of patient suicide on psychiatrists and psychiatric trainees. Academic Psychiatry, 28 (2), 104-110.

Sanders, C. (1989). Grief: The mourning after. New York: Wiley.

Sanders, C. (1999). Grief, the mourning after: Dealing with adult bereavement ( $2^{\text {nd }}$ ed.). New York: John Wiley. 
Schaefer, J. A., \& Moos, R. H. (2003). Bereavement experiences and personal growth. In M. Storebe, R. Hannson,W. Stroebe, \& H. Schut (Eds.), Handbook of bereavement research: Consequences, coping and care (pp. 145-168). Washington, DC: American Psychological Association.

Schwartz, R. E. (2004). Therapists' experience of client sudden death: A qualitative study. (Doctoral dissertation). Retrieved from ProQuest Dissertations and Theses Database, (UMI No. 3111010).

Servaty-Seib, H. L. (2004). Connections between counseling theories and current theories of grief and mourning. Journal of Mental Health Counseling, 26 (2), 125-145.

Shapiro, R. E. (1985). A case study: The terminal illness and death of the analyst's mother: Its effect on her treatment of a severely regressed patient. Modern Psychoanalysis, 10 (1), 31-46.

Shaver, P. R., \& Tancredy, C. M. (2001). Emotion, attachment, and bereavement: A conceptual framework. . In Stroebe M. S., Hansson R. O., Schut H., \& Stroebe W. (Eds.). Handbook of Bereavement Research: Consequences, coping, and care (pp. 6388). Washigton, DC: American Psychological Association.

Shuchter, S., \& Zisook, S. (1993). The course of normal grief. In Stroebe, M. S., Stroebe, W., \& Hansson, R. O. (Eds.), Handbook of bereavement: Theory, research and intervention (pp. 23-43). Cambridge, England: Cambridge University Press.

Stern, E. M. (1986). Three instances of the emergence of grief. The Psychotherapy Patient, 2 (1), 3-14.

Stroebe M. S., Hansson R. O., Schut H., \& Stroebe W. (Eds), (2008). Handbook of Bereavement Research and Practice. Washigton, DC: American Psychological Association. 
Stroebe M. S., \& Schut H. (1999). The dual process model of coping with bereavement: Rationale and description. Death Studies, 23, 197-224.

Stroebe M. S., \& Schut H. (2001). Models of coping with bereavement: A review. In Stroebe M. S., Hansson R. O., Schut H., \& Stroebe W. (Eds.). Handbook of Bereavement Research: Consequences, coping, and care (pp. 375-403). Washigton, DC: American Psychological Association.

Stroebe, M., Stroebe,W., \& Hannson R. (1993). Bereavement research and theory: An introduction to the handbook. In M. Strobe,W. Strobe, \& R. Hansson (Eds.), Handbook of bereavement: Theory, research and intervention (pp. 3-22). New York: Cambridge University Press.

Stroebe, W., \& Stroebe, M. (1987). Bereavement and health: The psychological and physical consequences of partner loss. New York: Cambridge University Press.

Strug, D., \& Podell, C. (2002). A bereavement support group for pediatric HIV/AIDS case managers and social workers: Helping members cope with dying children. Social Work with Groups, 25 (3), 61-75.

Sue, D. W., \& Sue, D. (1999). Counseling the culturally different $\left(3^{\text {rd }}\right.$ ed.). New York: Wiley.

Tsai, M., Plummer, M. D., Kanter, J. W., Newring, R. W., \& Kohlenberg, R. J. (2010). Therapist grief and functional analytic psychotherapy: Strategic self-disclosure of personal loss. Journal of Contemporary Psychotherapy, 40 (1), 1-10.

Ulman, K. (2001). Unwitting exposure of the therapist: Transferential and countertransferential dilemmas. The Journal of Psychotherapy Practise and Research, $10(1), 14-22$.

Valente, S. M. (1994). Psychotherapist reactions to the suicide of a patient. American Journal of Orthopsychiatry, 64 (4), 614-621.

Valentine, C. (2006). Academic constructions of bereavement. Mortality, 11 (1), 57-78. 
Vamos, M. (1993). The bereaved therapist and her patients. American Journal of Psychotherapy, 47 (2), 296-305.

Walter, T. (1996). A new model of grief? Bereavement and Biography Mortality, 1(1), 7-25.

Walter, T. (1999). On bereavement: The culture of grief. Oxford: Oxford University Press.

Wong, N. (1990). Acute illness in the analyst. In Schwartz, H. J, \& Silver, A. S. (Eds.), Illness in the analyst: implications for the treatment relationship (pp. 27-45). Madison, CT, US: International Universities Press.

Worden, W. J. (1982). Grief counseling and grief therapy: A handbook for the mental health practitioner. New York: Springer.

Worden, J. W. (1991). Grief counseling and grief therapy. A handbook for the mental health practitioner $\left(2^{\text {nd }}\right.$ ed.). New York: Springer Publishing Company

Worden, J. W. (2002). Grief counseling and grief therapy. A handbook for the mental health practitioner, (3rd ed.). New York: Springer Publishing Company.

Worden, J. W. (2009). Grief counseling and grief therapy. A handbook for the mental health practitioner, (4th ed.). New York: Springer Publishing Company.

Wortman, C. B., \& Silver, R. C. (1989). The myths of coping with loss. Journal of Consulting and Clinical Psychology, 57, 349-357.

Wortman, C. B., \& Silver, R. C. (2001). The myths of coping with loss revisited. In . In Stroebe M. S., Hansson R. O., Schut H., Stroebe W. (Eds.). Handbook of Bereavement Research: Consequences, coping, and care (pp. 405-429). Washigton, DC: American Psychological Association. 